\title{
Postvaccination mass psychogenic illness in an Iranian rural school
}

M.T. Yasamy, 'A. Bahramnezhad' ${ }^{2}$ and H. Ziaaddini'

$$
\begin{aligned}
& \text { اعتلال نفسي جاعي بعد التطعيم في ملرسة ريفية إيرانية }
\end{aligned}
$$

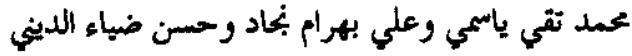

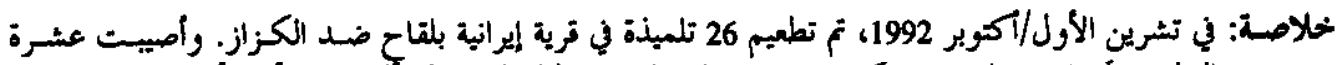

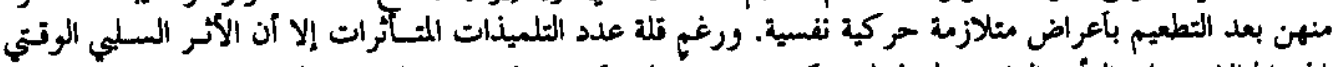

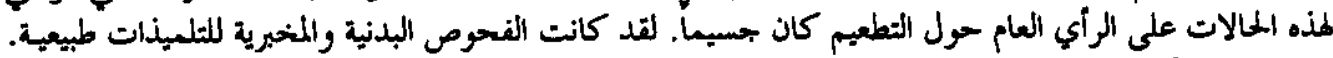

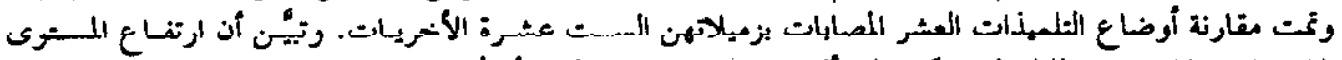

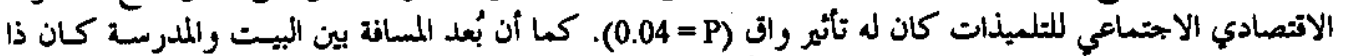

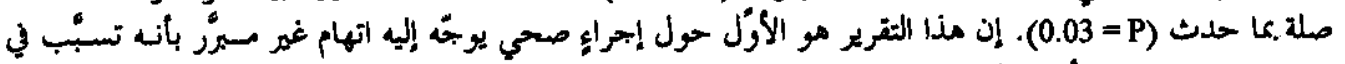

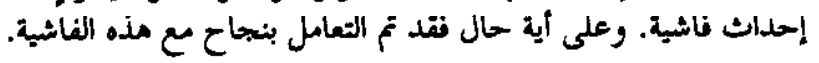

ABSTRACT In October 1992 after tetanus inoculations of 26 girl students in a village in the Islamic Republic of Iran, an outbreak of psychomotor syndrome occurred in 10. Although only few were affected, the temporary negative impact on public opinion about immunization was serious. Physical and laboratory investigations of the girls were normal. The 10 girls were compared with their 16 classmates. Higher socloeconomic status was protective $(P=0.04)$ and distance of home from school was relevant $(P=0.03)$. This is the first report of a health intervention unwarrantedly being held as the cause of an outbreak. The outbreak, however, was managed successfully.

\section{Maladie psychogène généralisée survenant après la vaccination dans une école iranienne en zone rurale}

RESUME En octobre 1992. après inoculation du vaccin tétanique à 26 écolières dans un village de la République islamique d'Iran, une flambée de syndrome psychomoteur est survenue chez dix d'entre elles. Bien qu'un petit nombre d'entre elles seulement aient été affectées, limpact négatif temporaire sur l'opinion publique à l'égard de la vaccination a été important. Les examens physiques et les analyses de laboratoire réalisées chez ces filles étaient normaux. Les 10 filles ont été comparées avec 16 de leurs camarades de classe. Le statut socio-économique plus élevé avait une valeur protectrice $(p=0,04)$ et la distance entre le domicile et l'école avait un rapport $(p=0,03)$. C'est le premier cas rapponé où une intervention sanltalre a été tenue pour cause d'une flambée épidémique de manière injustifiée. Toutefois, la flambée épidémique a été maîtrisée.

'Department of Psychiatry, Martyr Beheshti University of Medical Sciences, Tohoran, Islamic Republic of Iran.

"Mental Health Committee, Kerman Province, Islamic Republic of Iran.

'Department of Psychiatry, Kerman University of Medical Sciences, Islamic Republic of Iran.

Received: 02/09/97; accepted: 02/08/98 


\section{Introduction}

Mass psychogenic illness (MPI) is defined as the collective occurrence of a constellation of similar physical symptoms and related beliefs for which there is no plausible pathogenic explanation $[1,2]$. It is also known as epidemic or mass hysteria, and it has been defined as the occurrence of a constellation of physical symptoms suggesting an organic illness but resulting from a psychological cause in a group of individuals where each member experientes one or more of the symptoms [3]. The term "mass sociogenic illness" has been suggested as most cases have as much group or peer input as they have psychological explanation [4]. Sirois found 78 reports of outbreaks of epidemic hysteria during the previous hundred years (1872-1972) [5].

Outbreaks have become more common ever since, and reports have come from both industrialized and developing countries. The clinical presentation has been more or less the same worldwide. However, public opinion as to the cause of the outbreaks differs. In developing countries, the cause is more often ascribed to supernatural factors, whereas in industrialized countries it is more often thought to be a result of biological or chemical factors [3, 6-13].

Most incidents occur within closed, cohesive social settings [14]. Schoolchildren are especially prone to MPI and $60 \%$ of outbreaks in English reports have occurred in schools [3]. The incidence rate of MPI outbreaks is unknown, but Sirois has estimated that it occurs in $1 / 1000$ school settings per year in Quebec [5]. Small et al. have estimated that there are one to two outbreaks per year in the United States [8]. The only rebort from the Islamic Republic of Iran dates back to 1986 when an outbreak occurred in a school for girls [15]. This is the second report from this country and it is from the same province.

\section{The epidemic}

\section{Setting and background}

Hanza is a secluded village in a hilly area about $40 \mathrm{~km}$ from Rabor, a small town in Kerman Province. The houses are scattered and are considerable distances from each other, and the families are not as closely knit as in typical Iranian villages. The population is about 920 . The people's main livelihood is farming and cattle-raising. The village has been provided with pipeline water and electricity in the last decade, but there are still no public recreational facilities. The road to the village is not paved. There is one rural health centre with an auxiliary health house. The staff includes a general physician, a junior nurse (behyar), a health technician and a primary health care worker (behvarz).

The school is located in the remote north-west corner of the village. It is a middle school with approximately 75 girls from Hanza and satellite villages. The building is a robust medium-sized construction on an isolated hill with no campus, playground or social hall. The road to the school is very steep and uneven and some students have to walk a long way to school.

\section{Outbreak and Interventions}

On 6 October 1992, 2 weeks after starting a new school year, 26 students were vaccinated for tetanus as part of the routine immunization programme. Four days later, the first victim fainted in a classroom.

The index case had a history of similar attacks and had been receiving imipramine and perphenazine from a neurologist long before the outbreak. We later diagnosed her as having major depression and conversion

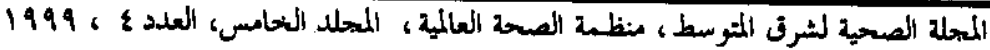


disorder. Her symptoms were pseudoseizures, tremor, blurred vision, headache, sweating and a burning sensation in her hands. She was transferred to the school office and then to the local health centre.

In the following days, nine others experienced a similar syndrome. All had pseudoseizures but none had hyperventilation. The first four cases were seen by the general practitioner in the rural health centre; he referred them to the paediatrician in the district health centre. The paediatrician in turn referred them to the University Hospital No. 1 to rule out encephalitis.

These first cases were hospitalized in the paediatric ward. All investigations by paediatricians, neurologists and internists, including physical examinations, lumbar punctures. laboratory tests and electroencephalography were normal and hysteria was diagnosed. The head of the department informed the university chancellor. The first and the second author were called for an urgent visit to the hospital. The possibility of an outbreak of mass hysteria was recognized. Immediate discharge of the patients was recommended and the patients and their parents were reassured about the condition.

The next day, the first two authors went to the village accompanied by the district paediatrician and other members of the local health authorities. By this time, 5 weeks had elapsed since the beginning of the outbreak. Teachers, administrators of the local educational system, local people and even most members of the local health authorities were convinced that the problem was a "brain disease" caused by faulty vaccines. A well known national newspaper had recently published a similar story. Although the outbreak was relatively small (on our arrival and subsequently only 10 people were afflicted), rumours were prevalent and public opinion was swaying considerably.
Local authorities, students and parents were invited to a meeting at our request. We had a preliminary briefing about the problem, then the first author volunteered to have an injection with the same vaccine and the same serial number.

After this injection, five afflicted students, who had been brought to the school were visited individually in the presence of a representative of the school and another of the parents. A physical examination was performed by the paediatrician; then the first author reassured the student that she did not have a brain disease caused by the vaccine but a psychological problem that was treatable. By simple suggestion, symptoms were induced and reduced in all of the students. Finally, an athletics race was held for the now healthy students and they were congratulated on being strong and healthy. Two students, including the index case, were managed at their homes in adjacent villages. Three who were hospitalized in the district hospital were discharged after the same interventions.

We recommended that all the stricken girls return to school without delay. Only three students had episodes during the following week and the outbreak ceased except for the symptoms of the index case. Appropriate feedback was given to the local authorities and to the educational staff to minimize stress to the girls. An investigation was initiated with the objective of determining the sociodemographic and psychometric factors that predisposed these students to MPI.

\section{Subjects and methods}

We compared the 10 victims with their 16 classmates 2 weeks after our first visit and 1 week after the end of the outbreak. A battery of tests, including the Adult Progressive 
Raven Mattrices and Minnesota Multiphasic Personality Inventory (MMPI) (both standardized to the Iranian population) and a questionnaire were used. The questionnaire was used to interview parents and teachers about demographic characteristics, socioeconomic status as perceived by the school teachers and the distance of the girls' homes from the school.

Data were analysed using the Student $t$ test for continuous data, chi-squared $\left(\chi^{2}\right)$ analysis and Fisher exact probability.

\section{Results}

The sociodemographic data are summarized in Table 1. Mean age was the same for both groups. Socioeconomic status (SES) as perceived by the teachers showed that those with high SES were affected less frequently $(P=0.04)$. No victim belonged to the high SES group but six from the control group did.

Mean distance of the school from home was $4930 \mathrm{~m}$ (standard deviation $=4340 \mathrm{~m}$ ) for the victims (median $=5000 \mathrm{~m}$ ) and 956 $\mathrm{m}$ (standard deviation $=1640 \mathrm{~m}$ ) for the control group (median $=500 \mathrm{~m}$ ). The difference was statistically significant $(P=$ 0.03 ). Only one student from the larger control groun but four students from the group of victims came from a distance of more than $5 \mathrm{~km}$.

No parent was divorced or separated in either group and parental loss did not differ between the two groups. Previous academic performance was not different for the two groups $(P=0.3)$. IQ as determined by Raven Progressive Mattrices was similar for the two groups. The results of the IQ and MMPI tests are summarized in Table 2. The MMPI profiles of both groups was normal and comparable. Statistical analysis us-

\section{Table 1 Sociodemographic cheracteristics of the subjects}

\begin{tabular}{|c|c|c|c|c|c|c|}
\hline \multirow[t]{2}{*}{ Characteristic } & \multicolumn{2}{|c|}{$\begin{array}{c}\text { Case } \\
(n=10)\end{array}$} & \multicolumn{2}{|c|}{$\begin{array}{l}\text { Control } \\
(n=10)\end{array}$} & \multicolumn{2}{|c|}{$\begin{array}{l}\text { Dlfference } \\
(\sigma=\mathbf{2 4})\end{array}$} \\
\hline & Mean & $s$ & Mean & 8 & $t$ & $\boldsymbol{P}$ \\
\hline Age (years) & 14 & 0.51 & 14.3 & 0.61 & 0.11 & 0.91 \\
\hline \multirow[t]{2}{*}{ Family size } & 6.8 & 2.2 & 6.6 & 2.3 & 0.26 & 0.79 \\
\hline & \multicolumn{2}{|c|}{ No. } & \multicolumn{2}{|c|}{ No. } & & \\
\hline \multicolumn{7}{|c|}{$\begin{array}{l}\text { Distance of home from } \\
\text { school (km) }\end{array}$} \\
\hline$<1$ & \multicolumn{2}{|c|}{3} & \multicolumn{2}{|c|}{10} & \multicolumn{2}{|l|}{$P=0.03^{a}$} \\
\hline $1-5$ & \multicolumn{2}{|c|}{3} & \multicolumn{2}{|c|}{5} & & \\
\hline$>5$ & \multicolumn{2}{|c|}{4} & \multicolumn{2}{|c|}{1} & & \\
\hline \multicolumn{7}{|c|}{ Socioeconomic status } \\
\hline High & \multicolumn{2}{|c|}{0} & \multicolumn{2}{|c|}{6} & \multicolumn{2}{|l|}{$P=0.04^{b}$} \\
\hline Medjum & \multicolumn{2}{|c|}{8} & \multicolumn{2}{|c|}{7} & & \\
\hline Low & \multicolumn{2}{|c|}{2} & \multicolumn{2}{|c|}{3} & & \\
\hline
\end{tabular}

" $x^{2}$ for limear trend $=4.5$

bFisher exact test after pooling medium and low socioeconomic status together

df = degrees of freedom

$s=$ standard deviation

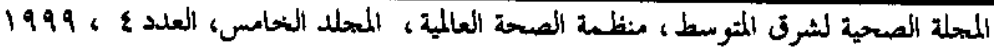




\begin{tabular}{|c|c|c|c|c|c|c|}
\hline \multirow[t]{2}{*}{ Characteristic } & \multicolumn{2}{|c|}{$\begin{array}{c}\text { Case } \\
(n=10)\end{array}$} & \multicolumn{2}{|c|}{$\begin{array}{l}\text { Control } \\
(n=16)\end{array}$} & \multicolumn{2}{|c|}{$\begin{array}{l}\text { Difference } \\
(d f=24)\end{array}$} \\
\hline & Mean & $s$ & Moan & 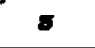 & $t$ & $P$ \\
\hline $1 \mathrm{Q}$ & 88.4 & 10.78 & 92.31 & 11.44 & 0.07 & 0.6 \\
\hline \multicolumn{7}{|l|}{ MMPI } \\
\hline L & 4 & 1.05 & 3.59 & 0.89 & 1.14 & 0.27 \\
\hline $\mathbf{F}$ & 3.5 & 1.78 & 4.18 & 2.28 & 0.81 & 0.43 \\
\hline $\mathbf{K}$ & 9.3 & 4.08 & 9.87 & 4.19 & 0.34 & 0.73 \\
\hline $\mathrm{Hs}$ & 5.4 & 1.57 & 5.25 & 1.18 & 0.28 & 0.78 \\
\hline $\mathbf{D}$ & 8.2 & 1.54 & 8.25 & 2.11 & 0.06 & 0.95 \\
\hline $\mathrm{Hy}$ & 10.7 & 3.4 & 10.80 & 2.60 & 0.15 & 0.89 \\
\hline $\mathbf{P d}$ & 4.3 & 1.59 & 5.81 & 2.04 & 2.00 & 0.06 \\
\hline $\mathbf{P a}$ & 4.7 & 0.48 & 5.31 & 4.06 & 2.72 & 0.01 \\
\hline Pt & 4.5 & 2.41 & 6.06 & 1.52 & 0.57 & 0.57 \\
\hline $\mathrm{Sc}$ & 5.9 & 2.02 & 6.81 & 2.88 & 0.87 & 0.39 \\
\hline Ma & 3.2 & 2.04 & 4.18 & 2.56 & 1.03 & 0.31 \\
\hline
\end{tabular}

df = deprees of freedom $\quad \mathrm{s}=$ standard deviation MMPI = Minnesota Multiphasic Personality inventory

ing the Student $t$-test showed no difference except higher scores on $\mathrm{Pa}$ for the controls.

\section{Follow-up}

Since the outbreak had significantly shifted villagers' attitudes towards vaccination, we were especially concerned about their reaction in the upcoming year. We planned another visit to the village at the time of vaccination. Nearly all teachers and most villagers seemed content that the procedure would not have side-effects. A few parents were worried and one mother declared that she would not consent. A group discussion ended with another voluntary shot of tetanus vaccine to the first author and some other local health staff and proved very successful. All parents and students cooperated and no physical or psychological side-effects occurred.

\section{Discussion}

According to Wessely, mass hysteria can be divided into two syndromes. Mass anxiety hysteria has an acute onset in which there is no initial case and no previous tension and has a better prognosis [16]. Mass motor hysteria has a more gradual onset and recovery and there is an initial case and previous tension. The previous epidemic in Kerman Province was of the first type [15], whereas the present outbreak was of the second.

The sample size of this study was small but our results should be considered. Higher socioeconomic status had a protective effect on the students. One particular source of stress, long school-to-home distance, proved to be an important predisposing factor. Remoteness of the school from home has been suggested as a possible contributor in at least one other outbreak [12]. 
A long sohool-to-home distance may have been a physical stressor and may have predisposed the students to MPI. We were not able to show any personality differenecs between the two groups. The issue is controversial and no personality characteristic has been shown to predispose people to MPI outbreaks $[9,14]$.

This outbreak had some important health-related aspects. To our knowledge, this is the first report in which a health intervention and not a noxious environmental agenl was perceived to have caused an MPI outbreak. A relationship has been reported between psychological vulnerability and subsequent hypersensitive reaction to inoculations [17]. Our patients' symptoms and signs were not compatible with local or systemic hypersensitivity or other organic conditions.

That the outbreak occurred after vaccination gave it particular significance. First, the outbreak might have had profound deleterious effects on public opinion toward immunization and even other health programmes. It is typical of MPI outbreaks that they are dramatically publicized $[1,10]$. In our case, people in more remote areas, influenced by the spreading rumours, were developing a negative attitude towards vaccination. Second, since termination of such outbreaks is dependent on reassurance, the unwarranted accusal of the health system makes termination more difficult. Fortunately, our efforts, although challenging, proved successful.

Closing schools has been suggested as a very early action to stop outbreaks $[18,19]$. We found it necessary to persuade the affected girls to attend school. We think that closing schools may be indicated in some cases of acute mass anxiety hysteria but not in the slowly progressing mass motor hysteria outbreaks. We recommend an individualized approach in different outbreaks.
In general, MPI outbreaks have been regarded as a collective psychiatric disorder. Bartholemew has criticized the view of psychiatrists in Europe and North Amcrica regarding this phenomenon [14]. Contrary to previous interpretations of MPI as a maladaptive behaviour, he suggests that the creative capacity of human beings helps them invent such collective responses.

The heterogeneous and multifaceted nature of mass behaviour should always be taken into consideration $[7,14]$ and the empathic approach posited by Bartholemew should be considered [14]. On many occasions, maladaptive aspects of such behaviour may predominate. Empathic understanding of the victims should be accompanied by urgent specialist interventions to terminate the outbreak [20] and prevent it from spreading with further deleterious consequences.

\section{Acknowledgements}

The authors would like to thank Professor S. Wessely for his helpful comments on the paper. We are also grateful to Dr M.H. Daei Parizi, Head, Department of Paediatrics, University Hospital No.1 and many other colleagues who examined the flrst cases. Thanks are due to: J. Matin, District Mental Health Coordinator, for his assistance in the fieldwork; Dr K. Jafari for his help in the physical examination of the students in the field; Dr S.S. Gudarzi for his assistance during the follow-up visit, and for reviewing the manuscript; the teachers and administrative staff of the school and all health administrators and staff members of the area. Special thanks are due to the students and their parents who cooperated with this research. 


\section{Roforoncos}

1. Olkinuora M. Psychogenic epidemics and work. Scandinavian joumal of work, environment and health, 1984, 10(6):501-15.

2. Hall EM, Johnson JV. A case study of stress and mass psychogenic illness in industrial workers. Journal of occupational modicino, 1989, 1(3):24.

3. Small GW, Nicholi AM. Mass hysteria among schooichildren: early loss as a predisposing factor. Archives of general psychiatry, 1982, 39(6):721-4.

4. Stahl SM. Illness as an emergent norm or doing what comes naturally. In: Colligan $\mathrm{M}$, Pennebaker J, Murphy $\mathrm{L}$, eds. Mass psychogenic illness: a social psychological analysis. Hillsdale, New Jersey, Lawrence Erlbaum, 1982:185-98.

5. Sirois F. Epidemic hysteria. Acta psychiatrica Scandinavica supplement, 1974, 252:1-46.

6. Chan M, Koo WC. Epidomic hystoria: a study of high risk factors. Occupational health and safety, 1983, 52(3):55-7.

7. Lee RLM, Ackerman SE. The sociocultural dynamics of mass hysteria: a case study of social conflict in West Malaysia. Psychiatry, 1980, 43(1):78-88.

8. Small GW et al. Mass hysteria among student performers: social relationship as a symptom predictor. American journal of psychiatry, 1991, 148(9):1200-5.

9. Brodsky CM. The psychiatric epidemic in the American workplace. Occupational medicine, $1988,3(4): 653-62$.

10. Teoh Jl. Soewondo S. Sidharta M. Epidemic hysteria in Malayan schools: an illustrative episode. Psychiatry, 1975, 33(8):258-68.
11. Wason S, Bausher JC. Epidemic "mass" hysteria. Lancet, 1983, 2(8352):731-2.

12. Dhadphale M, Shaikh SP. Epidemic hysteria in a Zambian school: "The mysterious madness of Mwinllunga". British joumal of psychiatry, 1983, 142(1):85-8.

13. Small GW, Borus JF. Outbreak of illness in a school chorus. Toxic poisoning or mass hysteria? New England journal of medicine, 1983, 308(11):632-5.

14. Bartholomew RE. Tarantism, dancing mania and demonopathy: the anthropolitical aspects of mass psychogenic illness. Psychological medicine, 1994, 24(2):281-306

15. Naseri K, Ziaaddini $H$. Bohavioural epidemic in adolescents of Kerman. Majalleye mohitshenasee [Journal of ecologyl, 1986, 13(14):115-28.

16. Wessely S. Mass hysteria: two syndromes? Psychological medicine, 1987, 17(1):100-20.

17. Canter A, Cluff LE, imboden JB. Hypersensitive reactions to immunization inoculations and the antecedent psychological vulnerability. Journal of psychosomatic research, 1972, 16(2):99-101.

18. Epidemic hysteria [Editorial]. British medical joumal, 1979, 2(6187):408-9.

19. Forrestier RM. Epidemic hysteria - divide and conquer [Letter]. Lancet, 1979, 2(6191):669.

20. Wessely S, Wardle CJ. Mass sociogenic illness by proxy: parentally reported epidemic in an elementary school (the current literature). British journal of psychiatry, 1990, 157(9):421-4. 